\title{
Approximation of the High-Temperature Fire Zone Based on Terra/MODIS Data in the Problem of Subpixel Analysis
}

\author{
E. I. Ponomarev ${ }^{a, b, c, *}$, K. Yu. Litvintsev ${ }^{d}$, E. G. Shvetsov ${ }^{b, c}$, K. A. Finnikov ${ }^{c}$, and N. D. Yakimov ${ }^{c}$ \\ ${ }^{a}$ Federal Research Center "Krasnoyarsk Science Center", Siberian Branch, Russian Academy of Sciences, \\ Krasnoyarsk, 660036 Russia \\ ${ }^{b}$ Sukachev Institute of Forest, Siberian Branch, Russian Academy of Sciences, Krasnoyarsk, 660036 Russia \\ ${ }^{c}$ Siberian Federal University, Krasnoyarsk, 660041 Russia \\ ${ }^{d}$ Kutateladze Institute of Thermophysics, Siberian Branch, Russian Academy of Sciences, Novosibirsk, 630090 Russia \\ *e-mail:evg@ksc.krasn.ru
}

\begin{abstract}
In this work, an improved approach of the pixel-based analysis of the Terra/MODIS imagery is proposed. The approach allows us to improve the accuracy in estimating characteristics of the combustion zone when detecting thermal anomalies. The investigation is carried out based on the imagery of active vegetation fires in Siberian forests by the MODIS radiometer in the spectral ranges of 3930 to 3990 and 10780 to $11280 \mu \mathrm{m}$ (bands 21 and 31, respectively). It is proposed to describe the approximation of the temperature profile of the fire front using an exponential function. Using the nonuniform approximation of the temperature distribution on the surface in the vicinity of the active combustion zone allows us to determine the portion of the active pixel of the Terra/MODIS image with the given temperature excess over the background temperature in it. This improves the accuracy in extracting active combustion zones and classifying the heat release rate at the subpixel level. This approach is applicable to monitoring fire development phases in the near real time mode.
\end{abstract}

Keywords: remote data, active burning zone, fire radiative power, intensity, approximation, sub-pixel analysis

DOI: $10.1134 / \mathrm{S} 0001433819080073$

\section{INTRODUCTION}

Detection of vegetation fires and instrument estimation of combustion characteristics is one of most important directions of the thematic analysis of remote sensing data (Bartalev et al., 2015; Bondur et al., 2016). The resolution of specialized satellite systems used in fire monitoring as a rule does not exceed $250 \mathrm{~m}$, and the best known Russian platforms of forest fire monitoring (ISDM of the Federal Forestry Agency and Kaskad of the Russian Ministry of Emergency Situations) handle satellite information with a spatial resolution of $1000 \mathrm{~m}$, which, at present, determines a limited set of available attributive parameters of fires-coordinates, area, and time. Early detection of fires is significantly limited because their characteristics can be detected only when carrying out the subpixel analysis based on reliable models of the integral signal formation in the image pixel including the small-size source of thermal anomaly. Theoretically (Justice et al., 1992), satellite methods allow us to detect a hot spot with an area of $100 \mathrm{~m}^{2}$; in practice, according to estimates, the probability of determining a hot spot with an area of 5000 to $6000 \mathrm{~m}^{2}$ and temperature of $700 \mathrm{~K}$ is $60-70 \%$ (Shvetsov, 2012). Development of new approaches for the effective estimation of hot spot parameters at different stages of fire growth remains a topical problem (Ichoku and Kaufman, 2005; Vermote et al., 2009; Safronov et al., 2015). At present, only a few works are available on the question of recording and processing data about the energy characteristics of thermally active zones for cases of fires in boreal forests (Ponomarev, 2014; Shvetsov and Ponomarev, 2015; Ponomarev et al., 2017), although the method was tested many times by examples of experimental fires with known characteristics (Ichoku and Kaufman, 2005; Wooster et al., 2005; Kumar et al., 2011). Therefore, development of methods for instrumental quantitative estimates of fire characteristics is at present not a completely solved problem in spite of the fact that works in this direction have been carried out since the second half of the 20th century (Byram, 1959; Dozier, 1981; Matson and Dozier, 1981).

In this work, to refine the solution of the problem of classifying thermally active zones at the subpixel level and estimating the heat release rate at different fire phases, the problem of approximating the temperature distribution of the active combustion front is considered. Based on the numerical calculations, the effectiveness of the exponential distribution function in interpreting Terra/MODIS (Moderate Resolution Imaging Spectroradiometer) imagery data for the determination of fire characteristics is analyzed. The 


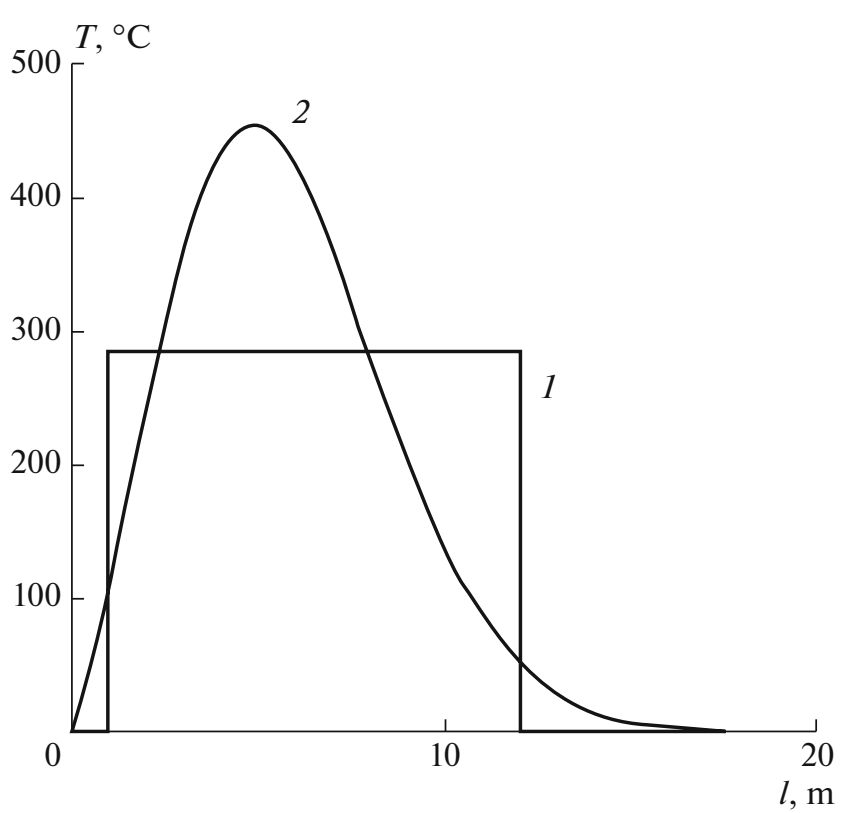

Fig. 1. General form of the surface temperature approximation $\left(T,{ }^{\circ} \mathrm{C}\right)$ in the region of an active subpixel (1) according to (Dozier, 1981) and (2) using an exponential function perpendicularly to the fire propagation front.

main objective of the work is to refine the method of the subpixel analysis of Terra/MODIS data. The following aspects of the problem were considered: (i) temperature profile of the active combustion zone and exponential approximation of the temperature perpendicularly to the propagation front of the active zone and (ii) comparative estimate of the effectiveness of the subpixel detection of thermal anomalies based on the proposed and standard (Dozier, 1981) approaches.

\section{INITIAL DATA AND METHODS}

This work involves the factual material collected on vegetation fires in Siberia according to the results of processing the Terra and Aqua/MODIS imagery during the period from 2003 to 2018 in the Sukachev Institute of Forest, a standalone subdivision of the Krasnoyarsk Science Center, Siberian Branch, Russian Academy of Sciences (Ponomarev and Shvetsov, 2015), as well as the maintenance support and materials of the Krasnoyarsk Multiple Assess Regional Center and Common Regional Center of Remote Sensing of the Krasnoyarsk Science Center.

In addition, standard MODIS products of the L2G and L3 processing levels were analyzed (https://lpdaac. usgs.gov/dataset_discovery/modis). Pixel-based data about the radiometric temperature in the ranges $\lambda=$ 3.93-3.99 (radiometer band 21) and 10.78-11.28 $\mu \mathrm{m}$ (bands 31 and 32) were calculated from the MOD11A1 product (Wan et al., 2015). The radiative power of active combustion zones were determined from MOD14/MYD14 Collection 5 products (Giglio et al.,
2016). The materials were processed using the technique for calculation of the fire radiative power (FRP) index characterizing the thermal emission power and combustion rate (Wooster et al., 2005; Kumar et al., 2011), as well as the technique of subpixel analysis based on the bispectral method (Dozier, 1981). The characteristics of the fire front were additionally refined based on materials of the Sentinel-2 imagery.

Based on the obtained and processed data of the satellite imagery, the effectiveness of the determination of the energetic and geometric characteristics of fires was analyzed. At the first stage, pixels corresponding to the fire were identified; then, the active subpixel portion allowing us to estimate the areas and rates of the active combustion zone was determined. For this purpose, the bispectral method (Dozier, 1981) is applicable. It fixes the active fire zone in a pixel of the Terra/MODIS images based on the values of the averaged temperature of the target and background. The solution is based on analyzing the rate of radiation of the active combustion zone. The rate is determined for the wavelength in the IR range $\lambda_{1}$ and $\lambda_{2}$ :

$$
\begin{gathered}
\left\{\begin{array}{c}
L_{\lambda_{1}}=\alpha L\left(\lambda_{1}, T_{m}\right)+(1-\alpha) L_{\lambda_{1}}^{0} \\
L_{\lambda_{2}}=\alpha L\left(\lambda_{2}, T_{m}\right)+(1-\alpha) L_{\lambda_{2}}^{0}
\end{array},\right. \\
L(\lambda, T)=\frac{c_{1}}{\lambda^{5}\left(e^{\frac{c_{2}}{\lambda T}}-1\right)},
\end{gathered}
$$

where $L(\lambda, T)$ is the Planck formula for the radiance, $\mathrm{W} /\left(\mathrm{m}^{3} \mathrm{sr}\right) ; \alpha$ is the portion of the active zone in the pixel; $L_{\lambda_{1}}$ and $L_{\lambda_{2}}$ are the radiation rates recorded in the ranges $\lambda_{1}$ and $\lambda_{2}$, respectively; $L_{\lambda_{1}}^{0}$ and $L_{\lambda_{2}}^{0}$ are the background radiation rates in the given ranges, respectively; $T_{\mathrm{m}}$ is the averaged temperature of the active combustion zone; $c_{1}=1.19 \times 10^{-16} \mathrm{~W} \mathrm{~m}^{2}$; and $c_{2}=$ $14.388 \times 10^{-2} \mathrm{~m} \mathrm{~K}$.

The main assumption of the bispectral method (Dozier, 1981) is the uniform distribution of the surface temperature in the active combustion zone (Fig. 1, curve 1). This can lead to a significant error in calculations of the fire area because the temperature distribution profile is not uniform. In this work, the temperature distribution was considered as an exponential function (Fig. 1, curve 2):

$$
\begin{gathered}
T\left(y, T_{\max }\right)=\left(T_{\max }-T_{0}\right) \\
\times\left[\left(\frac{n_{1}}{n_{2}}\right)^{\frac{n_{1}}{n_{2}}} e^{-\frac{n_{1}}{n_{2}}}\right]^{-1}\left(\frac{y}{Y}\right)^{n_{1}} e^{-\frac{(y)^{n_{2}}}{Y^{n_{2}}}}+T_{0}, Y>0,
\end{gathered}
$$

where the parameters $n_{1}$ and $n_{2}$ are responsible for the steepness of the front edge of the active fire zone and uniformity of the temperature profile, respectively; $T_{\max }$ is the maximum temperature, $T_{0}$ is the background temperature; $Y>0$ is the parameter characterizing the linear width of the active zone front, $\mathrm{m}$; and 


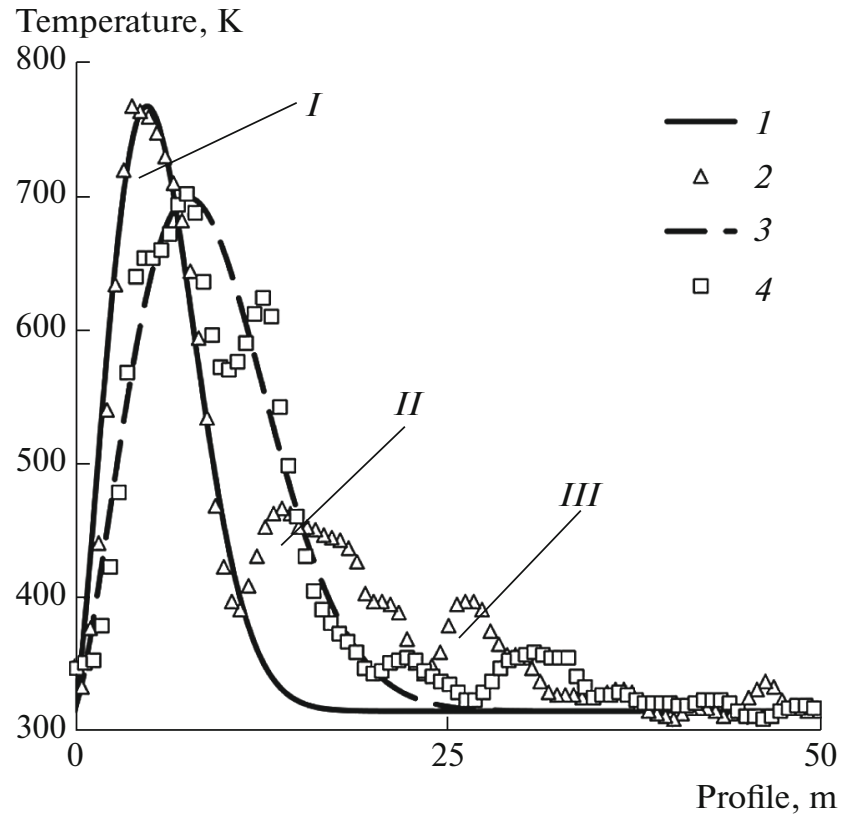

Fig. 2. Surface temperature distribution: $(2,4)$ field measurement data and $(1,3)$ their exponential approximations. Extreme values of temperature correspond to the $(I)$ fire front and residual spots of (II) combustion and (III) smoldering behind the fire front.

$y\left(T=T_{\max }\right)=-\sqrt[n_{2}]{n_{1} / n_{2}} Y$ is the coordinate of the temperature maximum.

When using this approximation, it is assumed that the width of the fire front is significantly less than its length. In this case, with allowance for (2), Eq. (1) is modified as follows:

$$
\begin{gathered}
\left\{\begin{array}{l}
L_{\lambda_{1}}=\alpha \bar{I}\left(\lambda_{1}, T_{\max }\right)+(1-\alpha) L_{\lambda_{1}}^{0}, \\
L_{\lambda_{2}}=\alpha \bar{I}\left(\lambda_{2}, T_{\max }\right)+(1-\alpha) L_{\lambda_{2}}^{0}
\end{array}\right. \\
\bar{L}\left(\lambda, T_{\max }\right)=\frac{1}{y_{2}-y_{1}} \int_{y_{1}}^{y_{2}} \frac{1.19 \times 10^{-16}}{\lambda^{5}\left(e^{\frac{1.44 \times 10^{-2}}{\lambda T\left(y, T_{\max }\right)}}-1\right)} d y,
\end{gathered}
$$

where $y_{1}=0$ and $y_{2}=3 Y$. In the case where $y_{1}$ and $y_{2}$ are linear functions of $Y$, the value $\bar{I}$ does not depend on $Y$.

Values of the parameters $n_{1}=1.3$ and $n_{2}=2$ were obtained based on the generalization of experimental data for fires in Siberia (McRae et al., 2005). Following the results of the generalization, model temperature curves were obtained (Fig. 2). In general, the proposed approximation of temperature allows us to sufficiently closely reproduce the temperature profile of the fire front. This approximation ignores low intensity combustion/smoldering regions which are observed as a rule behind the fire front (see Fig. 2, $I I$ and $I I I$ ).

In the solution of the system of equations (3), the magnitude of the active portion of pixel $\alpha$, in contrast to the standard method (Dozier, 1981), in fact does not determine the combustion region but characterizes the subpixel region with a temperature exceeding the background temperature. To determine the portion of the pixel with a given excess of the temperature $\Delta T_{a}$ over the background, it is necessary to find roots of Eq. (5) $y_{\alpha_{1}}$ and $y_{\alpha_{2}}$ in the interval $\left(y_{1} ; y_{2}\right)$ :

$$
\begin{aligned}
& \left(T_{\max }-T_{0}\right)\left[\left(\frac{n_{1}}{n_{2}}\right)^{\frac{n_{1}}{n_{2}}} e^{-\frac{n_{1}}{n_{2}}}\right]^{-1} \\
& \times\left(\frac{y}{Y}\right)^{n_{1}} e^{-\frac{y^{m_{2}}}{Y^{m_{2}}}}-\Delta T_{a}=0 .
\end{aligned}
$$

After the calculation of $y_{\alpha_{1}}$ and $y_{\alpha_{2}}$, the portion of the region $\alpha_{a}$ with the given $\Delta T_{a}$ is determined as follows:

$$
\alpha_{a}=\alpha \frac{\left|y_{\alpha_{2}}-y_{\alpha_{1}}\right|}{Y} .
$$

The ratio of active pixel portions calculated by Dozier's method $\left(\alpha_{D}\right)$ and modified bispectral method $\left(\alpha_{a}\right)$ with the temperature excess over the background $\Delta T_{a}$ is determined as

$$
A_{\Delta T}=\frac{\alpha_{a}}{\alpha_{D}} .
$$

To verify the effectiveness of the proposed approach, the comparative analysis of the subpixel characteristics (temperature and area of the active combustion zone) and results of the standard bispectral method (Dozier, 1981) was carried out. It involved a sample of pixels from Terra/MODIS images containing hot spots, with a volume of more than 23000 values. The considered image pixels corresponded to fires detected in Krasnoyarsk Angara Region (mainly, fires in pine forest stands), Evenkiya (fires in larch forests), and the left bank of the Yenisei River.

The power of fire radiation from a unit area of the active combustion zone was estimated using the standard bispectral method (Dozier, 1981) and the method with the exponential approximation of temperature with the use of different threshold excesses of the temperature to extract the active combustion zone. The volume of this sample amounted to 9500 fire Terra/MODIS pixels. For each pixel, values of the fire radiative power (FRP) were determined and subpixel areas of the high-temperature zone were calculated using the considered methods. Calculation of the areas by the proposed modified method involved the following values of threshold temperatures for the determination of the active combustion zone: 50, 100, 160 , and $200^{\circ} \mathrm{C}$. The fire radiative power from a unit area was calculated as the ratio of the total heat release power of a fire pixel to the area of the high-temperature zone.

The results were systematized and generalized by methods of mathematical statistics and correlation 
(a)

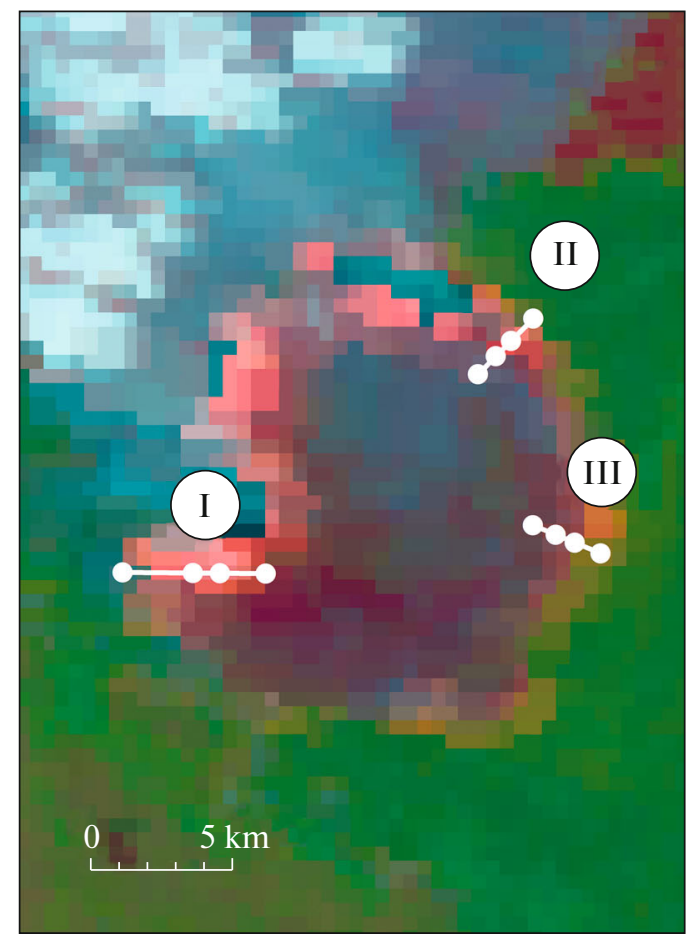

(b)

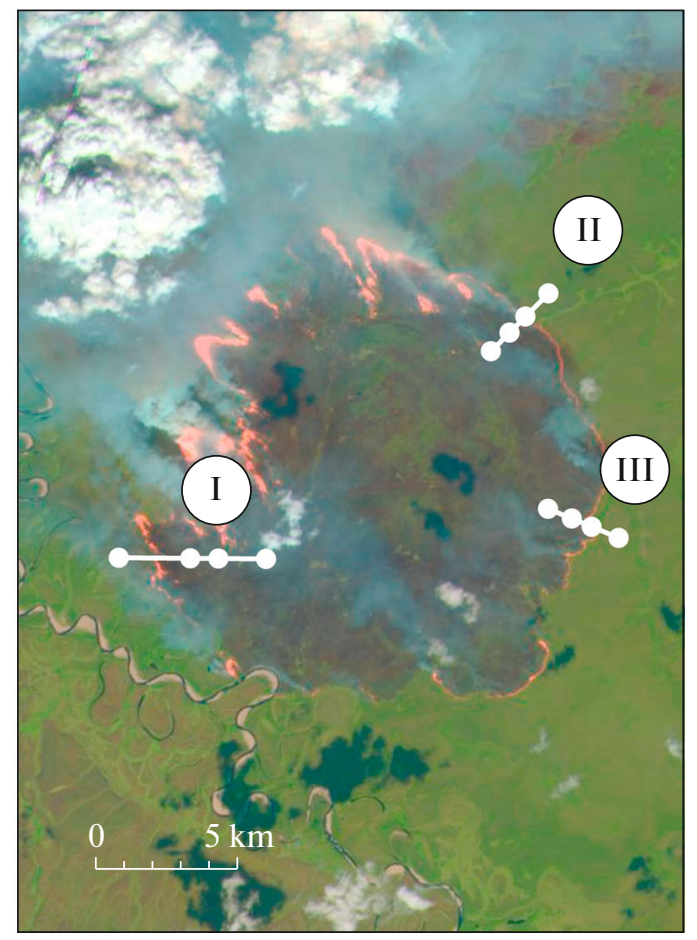

Fig. 3. Example of active fire shooting on (a) Terra/MODIS and (b) Sentinel-2 multispectral data. Profiles (I-III) of measurements of the brightness surface temperature in the range $\lambda=10.78-11.28 \mu \mathrm{m}$ (Terra/MODIS band 31).

analysis with the use of standard spreadsheets (MS Excel and MathCad). The statistical significance was estimated using the Mann-Whitney $U$-test (Gubler and Genkin, 1973).

\section{RESULTS AND DISCUSSION}

The resolution capability of satellite equipment does not allow us to directly obtain the fire data of this kind with the required accuracy. This is qualitatively illustrated in Fig. 3 which presents estimates of the radiometric temperature distribution over the profile using the survey by the Terra/MODIS and Sentinel-2 radiometers (with resolutions of 1000 and $15 \mathrm{~m}$, respectively). The degree of uncertainty in the obtained data about the brightness temperature is determined not only by the pixel size but also by spatial characteristics of the detected fire. In particular, the complex geometry of the active fire front is not always uniquely detected and separated when using low spatial resolution data; as a result, the recorded fire front can be represented by nonlinear groups of pixels with integral values of the brightness temperature in them (see Fig. 3, profile I). Below, the fire front's temperature profiles (see Fig. 2) approximated based on field measurements (McRae et al., 2005) are used as a calibration of satellite acquisition materials.

The statistical characteristics of active fire zone parameters (data of bands 21 and 31 of the MODIS radiometer) recorded for the test sample are presented in Table 1. Since the subpixel analysis used in this work is applicable only for surface fires, the table presents characteristics of fire pixels with the exception of the maximum temperatures (above the 90th percentile). This excluded the portion of pixels that corresponded with a high degree of probability to the crown fire phase that we do not deal with (Ponomarev et al., 2017).

The necessary condition for the correct operation of the bispectral method is the exact estimate of background characteristics primarily in the range of $11 \mu \mathrm{m}$. The radiation emitted by the background is estimated by analyzing the neighboring image pixels not containing hot spots. The differences in types of the vegetation cover, as well as the nonuniformity of the surface heating by the Sun or the presence of cooling areas passed by the fire earlier, can result in the fact that the signal received from adjacent pixels does not adequately characterize the signal emitted by the background portion of the fire pixel (Wooster et al., 2005). This problem is especially topical for low spatial resolution data, when background portions occupy the overwhelming majority of the fire pixel area. In particular, for cases of small-size or low-intensity fires, a signal detected in the thermal IR range from a fire pixel slightly differs from the background value calculated by the neighboring pixels. The results of temperature measurements in this range can be also affected by the spatial position of the fire bed within the MODIS pixel 
Table 1. Characteristics of variation in temperature and area of the active zone for the used test sample of pixels corresponding to the active fire phase

\begin{tabular}{|c|c|c|c|c|c|c|c|}
\hline \multirow{2}{*}{ MODIS band } & \multicolumn{2}{|c|}{$T, \mathrm{~K}$} & \multicolumn{5}{|c|}{ Temperature variation over the sample $(T, \mathrm{~K})$} \\
\hline & average & $\sigma$ & median & $\min$ & $\max$ & Percentile 10 & Percentile 90 \\
\hline 21 & 326.9 & 20.4 & 321.3 & 305.0 & 502.3 & 309.4 & 351.0 \\
\hline 31 & 294.6 & 6.3 & 295.2 & 271.2 & 400.1 & 286.7 & 301.6 \\
\hline $21 *$ & 298.7 & 6.9 & 300.4 & 276.3 & 320.0 & 288.8 & 306.7 \\
\hline \multirow[t]{4}{*}{$31 *$} & 291.9 & 5.9 & 292.7 & 268.3 & 306.7 & 283.9 & 298.9 \\
\hline & \multicolumn{2}{|c|}{$S, \mathrm{~km}^{2}$} & \multirow{2}{*}{\multicolumn{5}{|c|}{ Variation in the active zone area over the sample $\left(S, \mathrm{~km}^{2}\right)$}} \\
\hline & average & $\sigma$ & & & & & \\
\hline & 1.9 & 1.4 & 1.3 & 1.0 & 9.7 & 1.0 & 3.5 \\
\hline
\end{tabular}

* Measurements of background values.

(Peterson and Wang, 2013). For example, for the considered sample of fires, the temperature of about 1500 fire pixels in the thermal IR range was lower than the temperature of background pixels surrounding them. At the same time, for the middle IR range $(4 \mu \mathrm{m})$, this problem is not as topical and fire pixels whose signal was lower than the background value were not detected.

The obtained data did not take into account the influence of the scanning angle on the estimate of the area of the ground projection of the MODIS pixel because the error is not accumulated when the calculation results obtained for the subpixel analysis based on the considered approaches are compared. At the same time, it is known that the area of the pixel projection increases with an increase in the scanning angle (deviation from nadir). This, in the general case, leads to a decrease in the fraction of the area occupied by the fire bed within the limits of the pixel and, therefore, to a decrease in the contrast between the fire pixel and background in the thermal IR range. Due to the comparison of the two approaches, this uncertainty in fact had no effect on the results of the comparative analysis. In spite of the fact that the sample was not limited in the maximum scanning angle, the deviation from nadir for the main part $(68 \%)$ of MODIS pixels used in the analysis was within $30^{\circ}$ and their area did not exceed $1.7 \mathrm{~km}^{2}$. The average area amounted to about $1.9 \mathrm{~km}^{2}$.

The quantitative analysis of the processed fire pixels for which the portion of the active subpixel was determined using the method (Dozier, 1981) and modified bispectral method with a threshold excess of the temperature over the background $\Delta T_{a}$ demonstrates that the main part of the coincidence falls on values $\Delta T_{a}$ in the interval from 60 to $160^{\circ} \mathrm{C}$. Up to $15 \%$ of the pixels were detected outside the abovementioned range (Fig. 4). We can say that the concept of the active pixel portion has no clear definition when the standard method (Dozier, 1981) is used because there is in fact no given referencing to the energy characteristics of the fire. The high-temperature region which is taken into account in this method depends on the calculated average temperature determined to a considerable extent by the fire's intensity.

Figure 5 shows the dependence of the ratio $A_{\Delta T}$ (see (7)) on the averaged temperature for different $\Delta T_{a}$ in the modified method. In particular, for $\Delta T_{a}=60^{\circ} \mathrm{C}$, the coincidence of the methods is observed in the interval of averaged temperatures of 420 to $450^{\circ} \mathrm{C}$; for $\Delta T_{a}=140^{\circ} \mathrm{C}$, in the interval of 600 to $630^{\circ} \mathrm{C}$. For example, if we assume that an active subpixel is characterized by temperature exceeding the background values by $60^{\circ} \mathrm{C}$, the difference between the results of the two methods reaches $40 \%$ (see Fig. 5). In general, the overestimation of the active pixel portion in the standard approach is inversely proportional to the variation of the parameter $\Delta T_{a}$.

If we consider the dependence of the ratio of $\Delta T_{a}$ (when $\left.\alpha_{a}\left(\Delta T_{a}\right) \approx \alpha_{D}\right)$ to the averaged temperature $T_{D}$, then this quantity varies with a relatively small range from 0.4 to 0.5 . Therefore, based on the given $T_{\max }$ for the modified method, we can calculate $\Delta T_{a}$ for which the condition $\alpha_{a}\left(\Delta T_{a}\right) \approx \alpha_{D}$ is satisfied; i.e., the active subpixel portion is close to that calculated by the method of (Dozier, 1981) (Fig. 6). The exponential approximation of temperature, as noted above, is more effective because it is physically closer to the real temperature distribution on the surface of the active zone than the approximation used in the standard approach.

Another important problem related to the nonuniformity of the temperature distribution is the determination of $\Delta T_{a}$ for the active portion of the fire pixel. We can use two approaches: (i) specifying the $\Delta T_{a}$ and (ii) calculating $\Delta T_{a}$ from the condition of falling within the temperature range above $T_{0}+\Delta T_{a}$, providing more than $95 \%$ of the radiation energy of the considered range of $\lambda$. For example, when using the second 


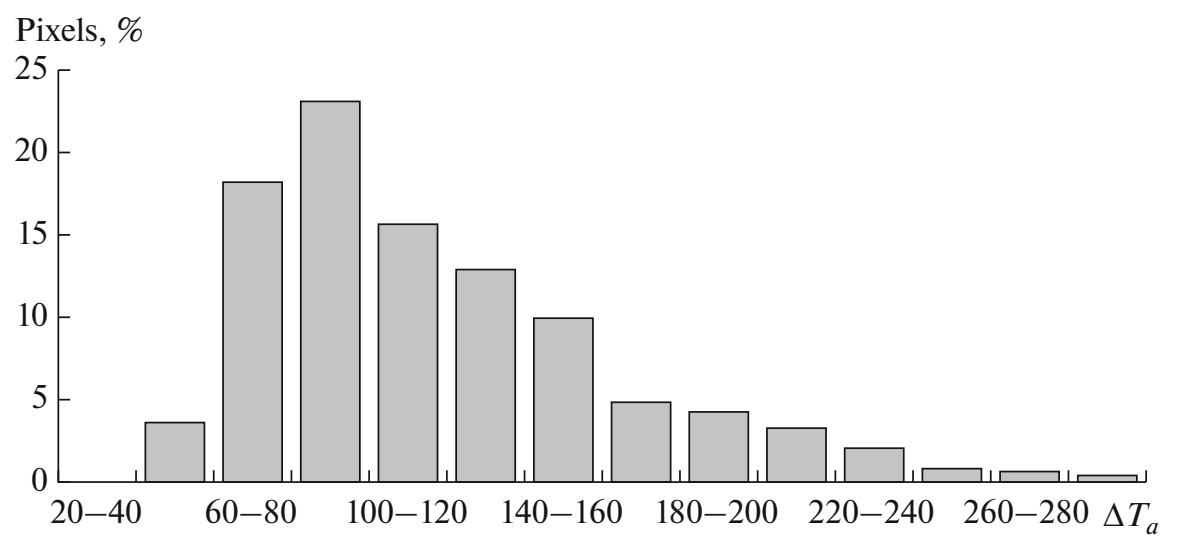

Fig. 4. Distribution of pixels over intervals $\Delta T_{a}\left({ }^{\circ} \mathrm{C}\right)$ for which portions of active subpixels calculated by the standard (Dozier, 1981) and modified methods coincide.

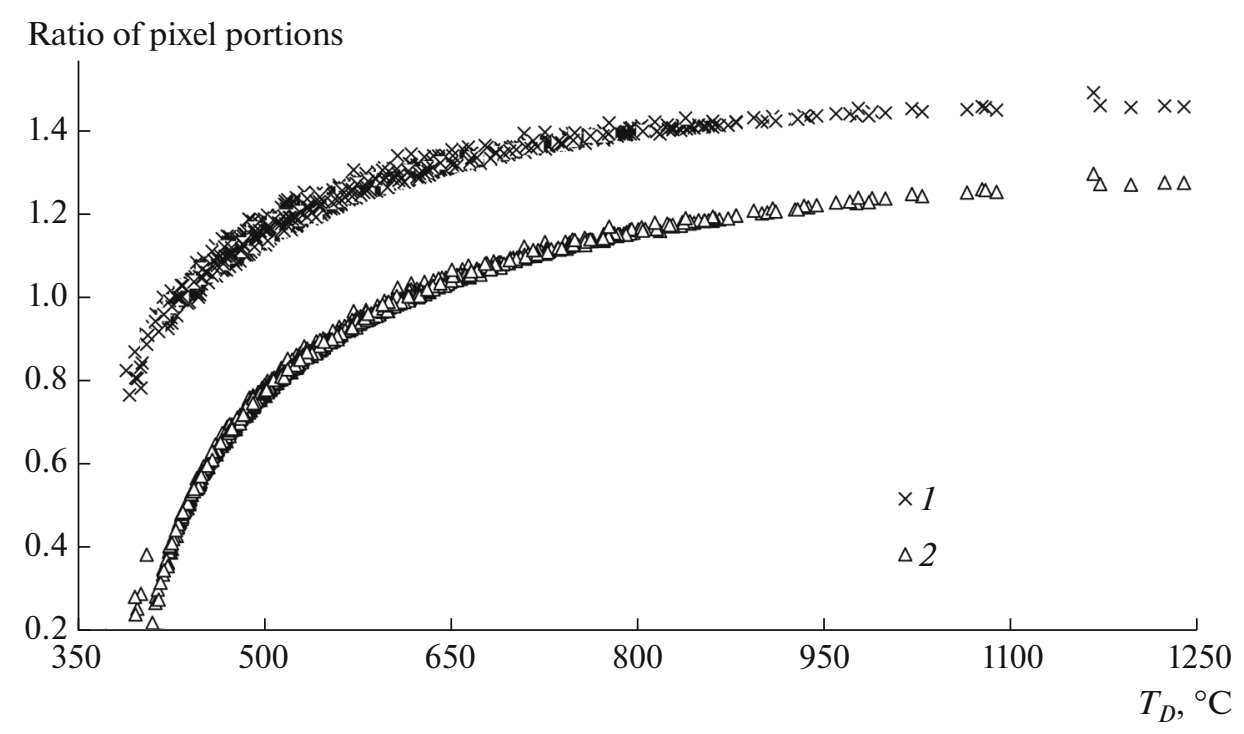

Fig. 5. Relationship of pixel portions when using the modified and standard approximations of temperature in the active combustion region for the bispectral method. $\Delta T$ is equal to (1) 60 and (2) $140^{\circ} \mathrm{C}$.

approach with $T_{\max }$ of about $720^{\circ} \mathrm{C}, \Delta T_{a}=235^{\circ} \mathrm{C}$; at $T_{\max }=450^{\circ} \mathrm{C}, \Delta T_{a}$ is only $64^{\circ} \mathrm{C}$.

If the proposed approximation of temperature is used for the bispectral method, its universality is the main question. For natural fires, it is apparently necessary to use a set of similar functions corresponding to different variations of the fire intensity. In any case, the results of the performed analysis demonstrate that the representation of the fire region as a region with a uniform temperature can lead to a significant error when estimating the active zone area at the subpixel level and intensity of the acting fire front. In particular, it is seen from the dependences presented in Fig. 1 that the area of the active zone for the uniform approximation corresponds to an excess of about $60^{\circ} \mathrm{C}$ over the background temperature compared to the expo- nential approximation; the averaged temperature here is lower than the maximum temperature approximately by $170^{\circ} \mathrm{C}$. These deviations vary depending on the recorded values of the radiation intensity. Therefore, the uniform distribution in each case determines the active zone area with an unknown temperature which cuts off the low-temperature region. Using a nonuniform approximation of the temperature distribution on the surface for the active combustion zone, in contrast to a uniform approximation, allows us to separate regions with different levels of the given temperatures, e.g., the region of high-intensity combustion.

With a change in the threshold values of the temperature, the discrepancy of the results obtained by the two considered methods is nonmonotonic (see Fig. 4). At the same time, a monotonic growth of the variance 


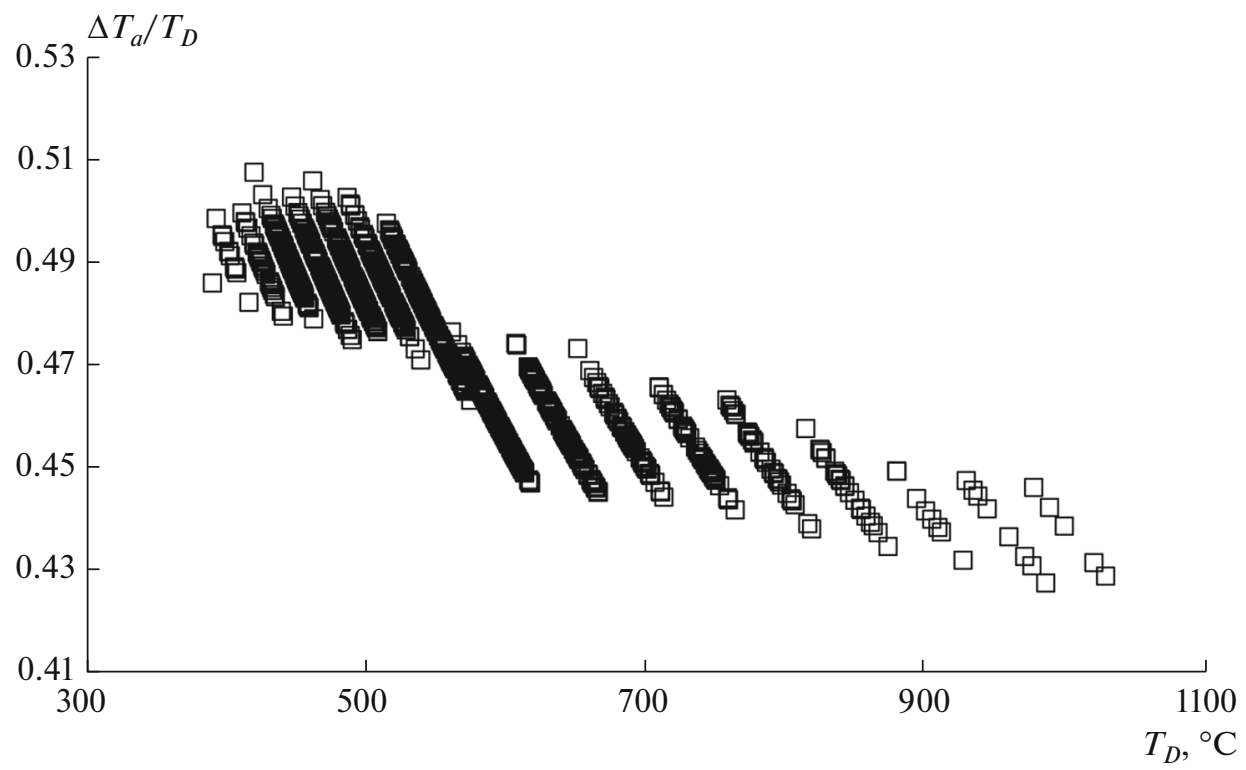

Fig. 6. Ratio of the threshold temperature to the averaged temperature calculated by the method of (Dozier, 1981) as a function of the fire intensity. The linear structure of the distribution is related to the interval-by-interval approximation of temperature.

(a)

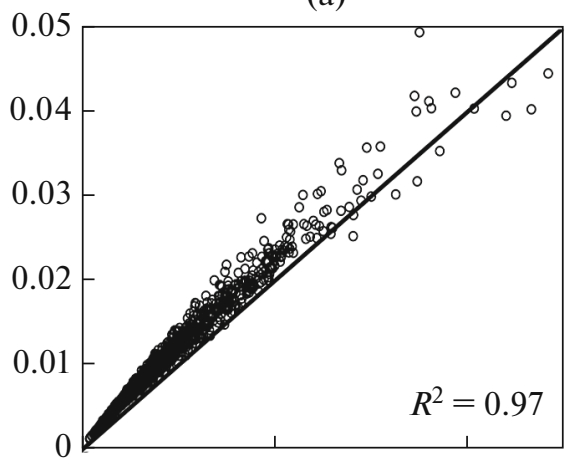

(d)

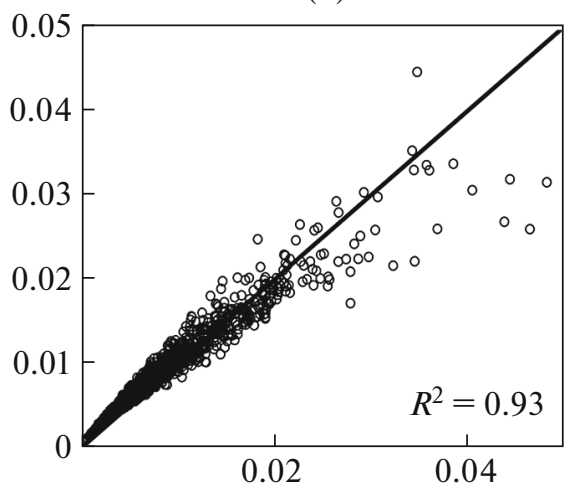

(b)

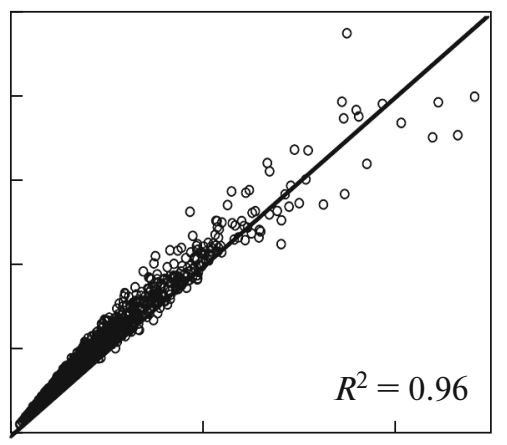

(e)

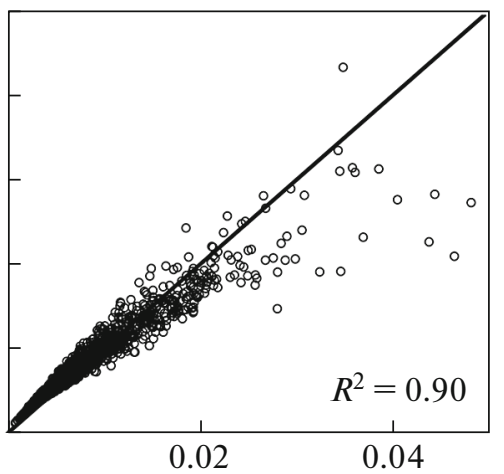

(c)

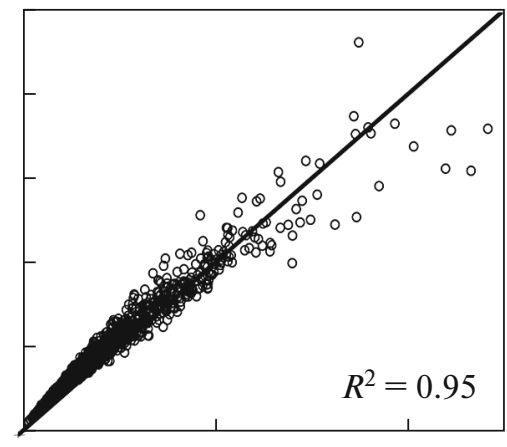

(f)

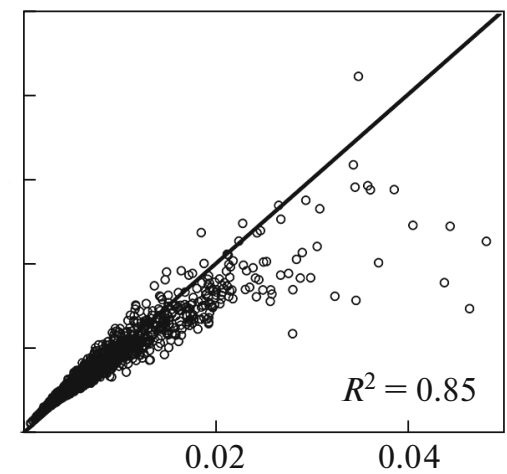

Fig. 7. Variation in the correlation field of the estimate of the active pixel portion with a change in the threshold temperature maximum of $50-100^{\circ} \mathrm{C}$. The threshold excess of temperature above the background $\Delta T_{a}$ is (a) 50 ; (b) 60 ; (c) 70 ; (d) 80 ; (e) 90 ; and (f) $100^{\circ} \mathrm{C}$. 
for the correlation field of the calculated active subpixel is observed (the validity coefficient for the linear approximation $R^{2}$ decreases from 0.97 to 0.85 ) (Fig. 7). This is related to the strong nonlinear dependence of the radiation intensity on temperature.

The major part of the considered fire pixels was characterized by the fire's radiative power values of up to $10 \mathrm{~kW} / \mathrm{m}^{2}$ (about $80 \%$ for larch forests of Evenkiya and about $65 \%$ for pine forests of the Angara Region). It has been found that, for the fire pixel sample used in the analysis, the subpixel area obtained by the standard bispectral method corresponds to the results obtained according to the method considered in this paper at the threshold temperatures of 120 to $140^{\circ} \mathrm{C}$. At lower threshold temperatures $\left(50\right.$ and $\left.100^{\circ} \mathrm{C}\right)$, the estimates of the subpixel areas were larger than according to the standard method and, as a consequence, the portion of pixels with low thermal radiation intensity (up to $5 \mathrm{~kW} / \mathrm{m}^{2}$ ) increased. At the same time, the higher values of the temperature threshold $\left(160\right.$ and $\left.200^{\circ} \mathrm{C}\right)$ yielded lower estimates of the subpixel area and higher thermal radiation intensities. In particular, at the threshold value of $200^{\circ} \mathrm{C}$, most fire pixels pass to the category of 5 to $10 \mathrm{~kW} / \mathrm{m}^{2}$.

\section{CONCLUSIONS}

The effectiveness of the subpixel analysis of the Terra/MODIS data based on the bispectral method in the problem of detection and description of thermal anomalies can be increased with the use of the nonuniform approximation of the temperature of the active fire zone. By the example of the proposed exponential approximation, it is shown that, in contrast to the standard method, only such an approach allows us to specify the determination of the active pixel portion of the Terra/MODIS image either via the excess of temperature in it over the background temperature or via the portion of the radiation energy. The discrepancy in the determination of the active pixel portion when using the considered approaches reaches tens of percent, which has a significant effect on the final classification of the heat release rate at the subpixel level according to the phases of the fire's evolution (e.g., phases recorded remotely in an expeditious manner).

At present, the main problem in using the nonuniform approximation of temperature is the accumulation of the empirical and, probably, calculated data on the temperature distribution on the surface in the active combustion zone for different types of natural fires with the aim of refining the proposed approximation function or creating a family of such functions.

\section{FUNDING}

This work was performed as part of state contract nos. 0356-2019-0009 (0356-2017-0739) and 0356-20180052 and was supported by the Russian Foundation for
Basic Research, Government of Krasnoyarsk krai, and Krasnoyarsk Regional Science Foundation (project nos. 17-41-240475 "Development of the mathematical model for the quantitative estimation of carbon emission during fires in Siberian forests based on remote instrument measurements" and 18-41-242003 "Modeling and satellite monitoring of effects from thermal anomalies of the underlying surface in the seasonally thawed soil layer of the permafrost zone of Siberia").

\section{CONFLICT OF INTEREST}

The authors declare that they have no conflict of interest.

\section{REFERENCES}

Bartalev, S.A., Stytsenko, F.V., Egorov, V.A., and Lupyan, E.A., Satellite assessment of fire-caused forest mortality in Russia, Lesovedenie, 2015, no. 2, pp. 83-94.

Bondur, V.G., Gordo, K.A., and Kladov, V.L., Spacetime distributions of wildfire areas and emissions of carboncontaining gases and aerosols in northern Eurasia according to satellite-monitoring data, Izv., Atmos. Ocean. Phys., 2017, vol. 53, no. 9, pp. 859-874. https://doi.org/10.1134/S0001433817090055

Byram, G.M., Combustion of forest fuels, Forest Fire: Control and Use, New York: McGraw-Hill, 1959, pp. 61-89.

Dozier, J., A method for satellite identification of surface temperature fields of sub-pixel resolution, Remote Sens. Environ., 1981, vol. 11, pp. 221-229.

Giglio, L., Schroeder, W., and Justice, C.O., The collection 6 MODIS active fire detection algorithm and fire products, Remote Sens. Environ., 2016, vol. 178, pp. 31-41.

Gubler, E.V. and Genkin, A.A., Primenenie neparametricheskikh kriteriev statistiki v mediko-biologicheskikh issledovaniyakh (The Use of Nonparametric Statistical Criteria in Medical and Biological Investigations), Leningrad, 1973.

Ichoku, C. and Kaufman, Y.J., A method to derive smoke emission rates from MODIS fire radiative energy measurements, IEEE Trans. Geosci. Remote Sens., 2005, vol. 43, pp. 2636-2649.

Justice, C.O., Malingreau, J.-P., and Setzer, A.W., Satellite remote sensing of fires: Potential and limitations, Fire in the Environment: The Ecological, Atmospheric, and Climatic Importance of Vegetation Fires, Crutzen, P.J. and Goldammer, J.G., Eds., Berlin, 1992, pp. 77-88.

Kumar, S.S., Roy, D.P., Boschetti, L., and Kremens, R., Exploiting the power law distribution properties of satellite fire radiative power retrievals: A method to estimate fire radiative energy and biomass burned from sparse satellite observations, J. Geophys. Res., 2011, vol. 116, D19303. https://doi.org/10.1029/2011JD015676

Matson, M. and Dozier, J., Identification of subresolution high temperature sources using a thermal IR sensor, Photogram. Eng. Remote Sens., 1981, vol. 47, no. 9, pp. 1311-1318.

McRae, D.J., Jin, J.-Z., Conard, S.G., Sukhinin, A.I., Ivanova, G.A., and Blake, T.W., Infrared characterization of fine-scale variability in behavior of boreal forest 
fires, Can. J. For. Res., 2005, vol. 35, no. 9, pp. 21942206.

Peterson, D. and Wang, J., A sub-pixel-based calculation of fire radiative power from MODIS observations: 2 . Sensitivity analysis and potential fire weather application, Remote Sens. Environ., 2013, vol. 129, pp. 231-249.

Ponomarev, E.I., Classification of Siberian fires in term of FRP-based radiation intensity according to Terra/MODIS data, Issled. Zemli iz Kosmosa, 2014, no. 3, pp. 56-64. https://doi.org/10.7868/S0205961414020080

Ponomarev, E.I. and Shvetsov, E.G., Satellite detection of forest fires and geoinformation methods of data calibration, Issled. Zemli Kosmosa, 2015, no. 1, pp. 84-91. https://doi.org/10.7868/S0205961415010054

Ponomarev, E.I., Shvetsov, E.G., and Usataya, Yu.O., Determination of the energy properties of wildfires in Siberia by remote sensing, Izv., Atmos. Ocean. Phys., 2018, vol. 54, no. 9, pp. 979-985. https://doi.org/10.1134/S000143381809030X

Safronov, A.N., Fokeeva, E.V., Rakitin, V.S., Grechko, E.I., and Shumsky, R.A., Severe wildfires near Moscow, Russia in 2010: Modeling of carbon monoxide pollution and comparisons with observations, Remote Sens., 2015, vol. 7 , no. 1 , pp. 395-429. https://doi.org/10.3390/rs70100395

Shvetsov, E.G., Probabilistic method for satellite detection and control of energy parameters of wildfires East Sibe- ria, Extended Abstract of Cand. Sci. (Tech.) Dissertation, Krasnoyarsk, 2012.

Shvetsov, E.G. and Ponomarev, E.I., Assessment of the impact of external conditions on heat radiation intensity from forest fires according to satellite monitoring data, Sib. Ekol. Zh., 2015, no. 3, pp. 413-421. https://doi.org/10.15372/SEJ20150308

Vermote, E., Ellicott, E., Dubovik, O., Lapyonok, T., Chin, M., Giglio, L., and Roberts, G.J., An approach to estimate global biomass burning emissions of organic and black carbon from MODIS fire radiative power, J. Geophys. Res., 2009, vol. 114, D18205, pp. 1-22. https://doi.org/10.1029/2008JD011188

Wan, Z., Hook, S., and Hulley, G., MOD11A1 MODIS/Terra Land Surface Temperature/Emissivity Daily L3 Global $1 \mathrm{~km}$ SIN Grid V006 (Dataset), NASA EOSDIS LP DAAC, 2015. https://doi.org/10.5067/MODIS/MOD11A1.006.

Wooster, M.J., Roberts, G., Perry, G.L.W., and Kaufman, Y.J., Retrieval of biomass combustion rates and totals from fire radiative power observations: FRP derivation and calibration relationships between biomass consumption and fire radiative energy release, J. Geophys. Res., 2005, vol. 110, D24311. https://doi.org/10.1029/2005JD006318

Translated by A. Nikol'skii 